W.A.C. Mutch MD, ${ }^{*}$ I.W.C. White MD, ${ }^{*}$ N. Donen MD, I.R. Thomson $\mathrm{MD}^{*}{ }^{*} \mathrm{M}$. Rosenbloom $\mathrm{BSc}_{\mathrm{c}}$ (HONS), ${ }^{*}$ M. Cheang MMath, $\dagger$ M. West MD $\ddagger$

\section{Haemodynamic insta- bility and myocardial ischaemia during carotid endarterectomy: a comparison of propofol and isoflurane}

The purpose of this study was to compare two anaesthetic protocols for haemodynamic instability (heart rate (HR) or mean arterial pressure $(M A P)<80$ or $>120 \%$ of ward baseline values) measured at one-minute intervals during carotid endarterectomy (CEA). One group received propofol/alfentanil (Group Prop; $n=14$ ) and the other isoflurane/alfentanil (Group Iso; $n=13$ ). Periods of haemodynamic instability were correlated to episodes of myocardial ischaemia as assessed by Holter monitoring (begun the evening before surgery and ceasing the morning of the first postoperative day). In Group Prop, anaesthesia was induced with alfentanil $30 \mu \mathrm{g} \cdot \mathrm{kg}^{-1} \mathrm{iv}$, propofol up to 1.5 $\mathrm{mg} \cdot \mathrm{kg}^{-1}$ and vecuronium $0.15 \mathrm{mg} \cdot \mathrm{kg}^{-1}$, and maintained with infusions of propofol at 3-12 $\mathrm{mg} \cdot \mathrm{kg}^{-1} \cdot \mathrm{hr}^{-1}$ and alfentanil at $30 \mu \mathrm{g} \cdot \mathrm{kg}^{-1} \cdot \mathrm{hr}^{-1}$. In Group Iso, anaesthesia was induced with alfentanil and vecuronium as above, thiopentone up to $4 \mathrm{mg} \cdot \mathrm{kg}^{-1}$ and maintained with isoflurane and alfentanil infusion. Phenylephrine was infused to support MAP at 110 $\pm 10 \%$ of ward values during cross-clamp of the internal carotid artery (ICA) in both groups. Emergence hypertension and/or

\section{Key words}

ANAESTHETICS, INTRAVENOUS: propofol;

ANAESTHETICS, VOLATILE: isoflurane;

HEART: ischaemia;

MONITORING: ECG, Holter;

SURGERY: carotid endarterectomy;

SYMPATHETIC NERVOUS SYSTEM: ephedrine, labetalol, phenylephrine, propranolol.

From the Departments of Anaesthesia*, Community Health Sciences $\dagger$ and Surgery (Section of Neurosurgery) $\downarrow$, University of Manitoba, Winnipeg, Manitoba, Canada.

Address correspondence to: Dr. Mutch, Department of Anaesthesia, St. Boniface General Hospital, 409 Tache Avenue, Winnipeg, Manitoba, Canada, R2H 2 A6.

Dr. Mutch is funded by the Medical Research Council of Canada and the Heart and Stroke Foundation of Canada. Accepted for publication 22nd February, 1995. tachycardia was treated with Labetalol, diazoxide or propranolol. Myocardial ischaemia was defined as ST-segment depression of $\geq 1 \mathrm{~mm}$ (60 msec past the J-point) persisting for $\geq$ one minute. For the entire anaesthetic course (induction to postemergence), there was no difference between groups for either duration or magnitude outside the $<80$ or $>120 \%$ range for $H R$ or MAP. However, when the period of emergence from anaesthesia (reversal of neuromuscular blockade to postextubation) was assessed, more patients were hypertensive ( $P$ $=0.004)$ and required vasodilator therapy in Group Iso (10) 13 vs 5/14; $P=0.038$ Fisher's Exact Test). The mean dose of labetalol was greater in Group Iso $(P=0.035)$. No patient demonstrated myocardial ischaemia during ICA cross-clamp. On emergence, 6/13 patients in Group Iso demonstrated myocardial ischaemia compared with $1 / 14$ in Group Prop (P $=$ 0.029). Therefore, supporting the blood pressure with phenylephrine, during the period of ICA cross-clamping, appears to be safe as we did not observe any myocardial ischaemia at this time. During emergence from anaesthesia, haemodynamic instability was associated with myocardial ischaemia. Under these specific experimental conditions, with emergence, hypertension and myocardial ischaemia were more prevalent with more frequent pharmacological interventions in patients receiving isoflurane.

Cette étude a pour objet de comparer deux protocoles anesthésiques conçus pour évaluer linstabilité hémodynamique (fréquence cardiaque ( $F c$ ) ou pression artérielle moyenne (PAM) $<80$ ou $>120 \%$ de la valeur initiale préopératoire) mesurée à des intervalles d'une minute pendant l'endartérectomie carotidienne (EAC). Un groupe reçoit propofol/alfentanil (groupe Propofol; $n=14$ ) et l'autre de l'soflurane/alfentanil (groupe Iso; $n=13$ ). Les périodes d'instabilité hémodynamique sont corrélées aux épisodes d'ischémie myocardique évalués par un monitorage de Holter (débuté le soir précédant la chirurgie et cessé le lendemain matin de lintervention). Dans le groupe Prop, l'anesthésie est induite avec de l'alfentanil, $30 \mu \mathrm{g} \cdot \mathrm{kg}^{-1}$ $\dot{\mathrm{n}}$, du propofol jusqu'à une dase maximale de $1,5 \mathrm{mg} \cdot \mathrm{kg}^{-1}$ 
et du vécuronium $0,15 \mathrm{mg} \cdot \mathrm{kg}^{-1}$, et entretenue avec une perfusion de propofol, de 3 a $12 \mathrm{mg} \cdot \mathrm{kg}^{-1} \cdot \mathrm{h}^{-1}$ et d'alfentanil, $30 \mu \mathrm{g} \cdot \mathrm{kg}^{-1} \cdot \mathrm{h}^{-1}$. Dans le groupe Iso, l'anesthésie est induite avec de lalfentanil et du vécuronium comme dans le groupe Prop, du thiopentone jusqu'à une dose maximale de 4 $\mathrm{mg} \cdot \mathrm{kg}^{-\mathrm{l}}$, et entretenue avec de lisoflurane et une perfusion d'alfentanil. Une perfusion de phényléphrine est utilisée pour maintenir une PAM à $110 \pm 10 \%$ de la valeur préopératoire pendant le clampage de lartère carotide interne $(A C I)$ dans les deux groupes. A la phase de réveil, lhypertension et/ou la tachycardie sont traitées avec du labétalol, du diazoxide ou du propranolol. L'sschémie myocardique est décelée par l'apparition d'une dépression du segment $S T \geq 1 \mathrm{~mm}$ (mesurée 60 msec après le point J) pour la durée diune minute et plus. Pour toute la durée de l'anesthésie (de linduction au réveil), il n'y a pas de différence entre les groupes tant pour la durée que pour l'importance des valeurs se situant en dehors de l'écart $<80$ et $>120 \%$ pour la Fc et la PAM. Cependant, à la période de réveil (de la décurarisation à l'extubation), plus de patients sont hypertendus $(P=0,004)$ et ont besoin d'un vasodilatateur dans le groupe Iso (10/13 vs 5/14); $P=0,038$ test d'exactitude de Fisher). La dose moyenne de labétalol est plus élevée dans le groupe Iso $(P=0.035)$. Aucun patient ne présente d'schémie myocardique pendant le clampage de l'ACI. Au réveil, 6/13 patients du groupe Iso présentent de lischémie myocardique comparativement à $1 / 14$ du groupe Prop $(P=0,029)$. Comme nous n'avons pas observé dischémie myocardique pendant la période de clampage de l'ACI, le soutien de la pression avec de la phényléphrine ne semble pas présenter de risque. $A$ la période du réveil, linstabilité hémodynamique est associée à l'ischémie myocardique. Sous ces conditions expérimentales spécifique, au réveil, l'hypertension et lischémie myocardique sont plus fréquentes et nécessitent plus d'interventions pharmacologiques chez les patients qui ont reçu de lisoflurane.

A major focus for managing patients undergoing carotid endarterectomy (CEA) is the prevention of cerebral and myocardial ischaemia during the operative procedure. Severe myocardial morbidity following this surgery is twice that of cerebral morbidity. ${ }^{1}$ Therefore, during CEA, intraoperative haemodynamic instability (excessive changes in heart rate (HR) or mean arterial pressure (MAP) should be minimized to maintain myocardial oxygen balance and thereby decrease the risk of myocardial ischaemia. It remains unclear which, if any, general anaesthetic regimen best assures intraoperative haemodynamic stability. Propofol is a newer intravenous anaesthetic agent which may be well suited for anaesthesia for CEA. It is associated with decreased requirements for vasodilator therapy to control hypertensive responses in the early postoperative period, ${ }^{2}$ a time of potential myocardial ischaemia. The requirement for such therapy is nearly $100 \%$ under certain circumstances during emergence with isoflurane anaesthesia. ${ }^{3}$ Also of potential benefit is that propofol is usually associated with a rapid emergence ${ }^{4}$ (within minutes of discontinuing an infusion) allowing prompt neurological assessment at completion of the procedure.

In this study we examined whether a continuous intravenous infusion of propofol was superior to inhaled isoflurane for anaesthetic management for CEA. It was our hypothesis that patients given propofol as their anaesthetic would have less haemodynamic instability intraoperatively. We predicted that the greater haemodynamic stability with propofol would be associated with a decreased incidence of myocardial ischaemia as assessed by continuous Holter monitoring.

\section{Methods}

This study was approved by the Faculty Committee on the Use of Human Subjects in Research at the University of Manitoba. Patients scheduled for carotid endarterectomy were studied. Excluded from study were patients with a pacemaker, left bundle branch block on preoperative ECG, myocardial infarction within three months of surgery, known alcohol or narcotic abuse or symptomatic reflux oesophagitis. Following consent and enrollment in the study, patients had their heart rate (HR) and blood pressure determined at least five times (Dinamap) before surgery to establish ward baseline values for these variables. In addition, Holter monitor (MEI 8500; bandwidth $0.05-80 \mathrm{~Hz} \pm 3 \mathrm{~dB}$ ) recording of leads II and CS5 was begun. Patients received all of their usual medications on the morning of surgery and 0.07 $\mathrm{mg} \cdot \mathrm{kg}^{-1}$ midazolam im one hour preoperatively. Supplemental oxygen was administered by nasal prongs at $3 \mathrm{~L} \cdot \mathrm{min}^{-1}$ concurrent with premedication. Upon arrival in the operating room the patient had intravenous and radial artery cannulae inserted following dermal infiltration with local anaesthetic. A five lead ECG (Siemens Sirecust 1281; bandwidth in diagnostic mode 0.05-100 $\mathrm{Hz} \pm 3 \mathrm{~dB}$ ) was placed for continuous monitoring of lead II and $V_{5}$. Lead placement was as close to the Holter monitor leads as was physically possible.

Haemodynamic data and end-tidal gas concentrations were recorded on an IBM PC-AT digital acquisition system at one-minute intervals. All clock times for data acquired to computer were synchronized to the Holter monitor. A five-minute period of baseline measurements was taken while the patient was breathing oxygen through the anaesthetic circuit. At this point the patients were randomized to either Group Iso or Group Prop.

Patients in Group Iso had anaesthesia induced with alfentanil $30 \mu \mathrm{g} \cdot \mathrm{kg}^{-1}$, thiopentone up to $4 \mathrm{mg} \cdot \mathrm{kg}^{-1}$ and 
isoflurane in oxygen. Muscle relaxation was achieved with vecuronium $0.15 \mathrm{mg} \cdot \mathrm{kg}^{-1}$. Anaesthesia was maintained with isoflurane in oxygen and a continuous infusion of alfentanil at $30 \mu \mathrm{g} \cdot \mathrm{kg}^{-1} \cdot \mathrm{hr}^{-1}$. Following induction, if mean arterial pressure (MAP) decreased by $>20 \%$ of ward baseline values, ephedrine $(2.5-5 \mathrm{mg}$ boluses) and/or phenylephrine by infusion was initiated. Ephedrine was used if heart rate (HR) decreased by $>20 \%$ of ward baseline values associated with the abovedescribed changes in MAP, otherwise phenylephrine was administered. If MAP exceeded $120 \%$ of baseline values then increasing concentrations of isoflurane were administered. Isolated decreases in HR by $>20 \%$ were treated by bolus doses of glycopyrrolate $(0.2 \mathrm{mg})$, if deemed necessary; $\mathrm{HR}<40$ beats $\cdot \mathrm{min}^{-1}$, escape rhythms etc. Increases in HR above $120 \%$ of baseline values were treated by increasing the depth of anaesthesia or, if persistent, by bolus administration of propranolol (0.5-1 mg). During cross-clamping of the carotid artery, MAP was maintained at $110 \pm 10 \%$ of baseline values by decreasing the isoflurane concentration, if necessary, and administering phenylephrine by infusion. With closure of the deep fascial layers in the neck, isoflurane was discontinued. Reversal of the vecuronium was with glycopyrrolate 0.005 $\mathrm{mg} \cdot \mathrm{kg}^{-1}$ and neostigmine $0.05 \mathrm{mg} \cdot \mathrm{kg}^{-1}$. Alfentanil infusion ceased with start of skin closure. The time until the tracheal was extubated and the patient could follow the command "squeeze my fingers" was noted. Requirement for vasodilators or vasopressors and their dose during emergence was recorded.

Patients in Group Prop had anaesthesia induced with alfentanil $30 \mu \mathrm{g} \cdot \mathrm{kg}^{-1}$ and propofol up to $1.5 \mathrm{mg} \cdot \mathrm{kg}^{-1}$, and muscle relaxation with vecuronium $0.15 \mathrm{mg} \cdot \mathrm{kg}^{-1}$. Anaesthesia was maintained with a continuous infusion of propofol at $3-12 \mathrm{mg} \cdot \mathrm{kg}^{-1} \cdot \mathrm{hr}^{-1}$ and alfentanil at 30 $\mu \mathrm{g} \cdot \mathrm{kg}^{-1} \cdot \mathrm{hr}^{-1}$. Following induction, if MAP decreased by $>$ than $20 \%$ of baseline values, ephedrine and/or phenylephrine by infusion was initiated as above. Ephedrine was used if HR decreased by $>20 \%$ of ward baseline values associated with the above-described changes in MAP, otherwise phenylephrine was administered. If MAP exceeded $120 \%$ of baseline values then an increased amount of propofol was administered. Isolated decreases in HR by $>20 \%$ were treated by bolus doses of glycopyrrolate $(0.2 \mathrm{mg})$, as above. Increase in HR above $120 \%$ of baseline values was treated by increasing the depth of anaesthesia or, if persistent, by bolus administration of propranolol. During cross-clamping of the carotid artery, MAP was maintained at $110 \pm 10 \%$ of baseline values by decreasing the propofol concentration to $3 \mathrm{mg} \cdot \mathrm{kg}^{-1} \cdot \mathrm{hr}^{-1}$, if necessary, and administering phenylephrine by infusion. The propofol was discontinued with closure of the deep fascial layers and reversal of vecuronium and cessation of alfentanil infusion occurred with start of skin closure.

Opioid effects were reversed with naloxone $(0.04 \mathrm{mg}$ increments) if assisted ventilation was required to maintain end-tidal $\mathrm{CO}_{2}<45 \mathrm{mmHg}$, five minutes after evidence of reversal of neuromuscular blockade was demonstrated with sustained tetanus at $50 \mathrm{~Hz}$.

\section{Estimated sample size}

The experiment was designed to test the hypothesis that intraoperative haemodynamic instability (outside of \pm $20 \%$ of ward baseline values for HR and/or MAP) was more frequent with isoflurane anaesthesia. Our own research indicated that antihypertensive therapy was required in all patients in certain subgroups during emergence from isoflurane anaesthesia following neurosurgical procedures. ${ }^{3}$ For patients anaesthetized with propofol, we predicted a 50\% reduction in antihypertensive therapy as an index of haemodynamic stability based on lower utilization of such therapy in the perioperative period as outlined by Monk et al. ${ }^{2}$ To achieve a power $=0.80$ at an $\alpha=0.05$, a minimum of 11 experiments were predicted in each group. We elected to study 30 patients with an expectation of some failed experiments.

\section{Surgical management}

The surgical management was as previously described. ${ }^{5}$ Briefly, vascular shunts during cross-clamping of the internal carotid artery were never used and no electroencephalographic (EEG) monitoring was undertaken. Prior to arteriotomy, 0.5 to $1 \mathrm{ml}$ of lidocaine $1 \%$ was injected into the adventitial tissue at the carotid artery bifurcation to block baroreceptor afferent impulses from the carotid sinus nerve. Primary closure of the vessel wall was accomplished without patch graft and, at the completion of the surgical procedure, the heparin administered for anticoagulation during the period of common carotid occlusion was not reversed with protamine.

If intraoperative ECG monitoring indicated the presence of myocardial ischaemia (ST-segment depression of $\geq 0.1 \mathrm{mV}$ persisting for $\geq$ one minute) in any patient, prompt treatment was instituted. Appropriate changes in anaesthetic depth, control of the blood pressure and administration of intravenous propranolol and/or nitroglycerine was initiated. The surgeon was notified of the episode of myocardial ischaemia. If patients emerged from anaesthesia with a new neurological deficit, discussion with the neurosurgeon as to the need for angiography and/or reoperation occurred immediately.

All patients were admitted to the surgical intensive care unit. Postoperative care focused on optimal control of the patient's blood pressure which continued to be monitored invasively via the radial artery cannula. Require- 
ment for vasodilator and/or vasopressor therapy was recorded. An ECG was obtained at $24 \mathrm{hr}$ postoperatively. Cardiac enzymes (CK-MG) were measured at 6 and 24 hr postoperatively. Holter monitoring was continued until the morning of the first postoperative day. The study ended with cessation of Holter monitoring.

\section{Assessment of haemodynamic instability}

Haemodynamic instability was defined as HR or MAP $<80$ or $>120 \%$ of ward baseline values. For each patient, HR and MAP were acquired at one-minute intervals intraoperatively. These data were analyzed post hoc to determine the magnitude and time that HR and MAP were outside of the $80-120 \%$ window. The area under or over the curve outside the target window and the percentage of time outside range was calculated. The entire time course of the anaesthetic (induction to postemergence) was evaluated for each patient. In addition, specific intraoperative time periods were also examined: (1) induction (immediate pre-induction to two minutes post-intubation), (ii) cross-clamp period (from one minute before application of ICA cross-clamp to one minute after removal of clamp), and (iii) emergence (reversal of neuromuscular blockade to post-extubation).

\section{Assessment of myocardial ischaemia}

The Holter monitoring tapes were analyzed using Diagnostic Medical Instruments computer hardware and software (version 5.02). A positive episode of myocardial ischaemia was defined by ST-segment depression of $\geq 1$ $\mathrm{mm}(60 \mathrm{msec}$ past the $\mathrm{J}$ point) for $>$ one minute. The baseline for ST-segment analysis was determined by scanning the entire Holter tape to detect a $\geq$ ten-minute period when the ST-segment was minimally depressed or elevated versus the normal isoelectric position if isoelectricity was not present. Changes in the ST-segment were measured from this baseline. Episodes suggestive of myocardial ischaemia were identified by the computer analysis system and were independently confirmed or rejected, following downloading to paper hard copy, by an observer blinded to the anaesthetic protocol (IRT). Postoperative myocardial infarction was diagnosed if: (i) the MB-CK fraction was $\geq 70 \mathrm{U} \cdot \mathrm{L}^{-1}$ and $\geq 5 \%$ of the total $\mathrm{CK}$. The MB-CK was considered elevated (an index of myocardial damage) if $\geq 35 \mathrm{U} \cdot \mathrm{L}^{-1}$ and $\geq 5 \%$ of total CK and/or (ii) the postoperative ECG indicated new Q-waves compared with the preoperative trace.

\section{Post-hoc data analysis}

Haemodynamic stability was assessed in each patient based on the data collection every minute for HR and MAP by downloading data from the Siemens Sirecust 1281 monitor to proprietary software from the Siemens
Corporation. End-tidal gas data were downloaded every minute from a Bruel \& Kjaer Anaesthetic Gas Monitor Type 1304 to DESQview Link communications software.

\section{Statistical analysis}

Between group comparisons (Group Iso versus Group Prop and ischaemic group versus non-ischaemic group by Holter monitoring) for parametric data were by Student's $t$ test. All continuous data are expressed as mean $\pm \mathrm{SD}$. Between group comparisons for non-parametric data were by $2 \times 2$ contingency tables using Fisher's Exact Test or Chi-square Test $(P \leq 0.05$ considered significant). For contingency tables of greater dimension the Wilcoxon Rank Sum Test was used $(P \leq 0.05$ considered significant). Data examining periods of haemodynamic instability were analyzed by Kruskal-Wallis Test (ChiSquare approximation; $P \leq 0.05$ considered significant). These haemodynamic changes were correlated with the ST-segment changes following analysis of the Holter monitoring tapes.

\section{Results}

Thirty patients were studied. Three patients were removed from analysis; one patient was removed from each group due to failed Holter monitoring records and in one experiment the computer data acquisition failed (Group Prop). The remaining 27 patients who were subsequently found to have good quality ECG traces from the Holter monitoring tapes form the basis of this report. All patients had surgery by the same neurosurgeon (MW). The demographic data are displayed in Table I. The two groups were similar with regard to age, incidence of ischaemic heart disease, diabetes, hypertension, obesity and smoking history. No attempt was made to risk stratify patients based on the classification of Sundt et al. ${ }^{6}$ However, there was no difference $(P=0.363)$ in the percentage of patients who were Risk Group 3 (total morbidity and mortality of $7 \%)^{6}{ }^{6}$ These patients are neurologically stable but have major medical risk (as defined in Table I) \pm major angiographic risk. Preoperative medications for both groups of patients are shown in Table II. There was no difference between the two groups regarding anti-anginal or any other medications. Of the 27 patients studied five participated in the North American Symptomatic Carotid Endarterectomy Trial (NASCET). ${ }^{7}$ Three patients with carotid stenosis $>90 \%$ crossed over to surgical from medical management following release of the NASCET results (two in Group Iso and one in Group Prop). Two patients were studied (both in Group Iso) having been prospectively randomized to surgical management with moderate level carotid stenosis (50 and 55\%). All other patients were managed similarly but had ipsilateral carotid stenosis of $>70 \%$ (88 $\pm 16 \%$ in Group Iso 
TABLE I Patient demographics

\begin{tabular}{llll}
\hline Variable & Isoflurane (\%) & Propofol (\%) & P-value \\
\hline$n$ & 13 & 14 & \\
Age (yr) & $65 \pm 7$ & $68 \pm 6$ & NS \\
Age $>70$ yr & $2(15)$ & $7(50)$ & NS \\
Angina & $4(31)$ & $4(29)$ & NS \\
MI previous 6/12 & $0(0)$ & $1(7)$ & NS \\
Previous MI & $5(38)$ & $6(43)$ & NS \\
Previous CABG & $1(8)$ & $2(14)$ & NS \\
Severe hypertension & & & \\
$\quad>180 / 110$ (mmHg) & $1(8)$ & $1(7)$ & NS \\
Peripheral vascular & & & \\
$\quad$ disease & $3(23)$ & $4(29)$ & NS \\
COPD & $3(23)$ & $2(14)$ & NS \\
Obesity & $2(15)$ & $0(0)$ & NS \\
Diabetes & $2(15)$ & $1(7)$ & NS \\
Smoker & $10(77)$ & $8(57)$ & NS \\
Risk group 3* & $11(85)$ & $10(71)$ & NS \\
\hline
\end{tabular}

Parametric data analyzed by unpaired $t$ test.

Non-parametric data analyzed by Fisher's Exact Test.

MI = myocardial infarction; $\mathrm{CABG}=$ coronary artery bypass

grafting; $C O P D=$ chronic obstructive pulmonary disease.

Obesity defined as body mass index $>30$.

* See text and reference 6.

Mean $\pm S D$ for parametric data.

NS = not significantly different.

TABLE II Patient medications

\begin{tabular}{llll}
\hline Medication & Isoflurane (\%) & Propofol (\%) & P-value \\
\hline$n$ & 13 & 14 & \\
ECASA & $11(85)$ & $10(71)$ & NS \\
B-blocker & $5(38)$ & $3(21)$ & NS \\
Calcium channel blocker & $3(23)$ & $3(21)$ & NS \\
Nitrates & $2(15)$ & $3(21)$ & NS \\
\hline
\end{tabular}

Non-parametric data analyzed by Fisher's Exact Test.

ECASA = enteric coated acetylsalicylic acid.

$N S=$ not significantly different.

and $84 \pm 13 \%$ in Group Prop; $P=0.478$ unpaired $t$ test).

\section{Intraoperative anaesthetic management}

Patients in Group Iso had anaesthesia induced with 3.2 $\pm 0.9 \mathrm{mg} \cdot \mathrm{kg}^{-1}$ thiopentone following $30 \mu \mathrm{g} \cdot \mathrm{kg}^{-1} \mathrm{al}-$ fentanil. Patients in Group Prop had anaesthesia induced with $1.3 \pm 0.3 \mathrm{mg} \cdot \mathrm{kg}^{-1}$ propofol following $30 \mu \mathrm{g} \cdot \mathrm{kg}^{-1}$ alfentanil. Intraoperative management and events are shown in Table III. Post-induction hypotension was similar in the two groups. Hypotension was treated with vasopressors in 8/13 patients in Group Iso and 6/14 patients in Group Prop $(P=0.695)$. Most patients were treated with bolus dose ephedrine. Persistent hypotension was treated with continuous infusion of phenylephrine. Iso-
TABLE III Intraoperative management and events

\begin{tabular}{|c|c|c|c|}
\hline Event & Isoflurane (\%) & Propofol (\%) & $P$-value \\
\hline$n$ & 13 & 14 & \\
\hline Vasopressor on induction & $8(62)$ & $6(43)$ & NS \\
\hline $\begin{array}{l}\text { Glycopyrrolate on } \\
\text { induction }\end{array}$ & $4(31)$ & $2(14)$ & NS \\
\hline $\begin{array}{l}\text { Total intraoperative } \\
\text { phenylephrine dose }(\mu \mathrm{g})\end{array}$ & $3916 \pm 3182$ & $2702 \pm 1074$ & $0.005^{*}$ \\
\hline $\begin{array}{l}\text { Carotid cross-clamp } \\
\text { duration (min) }\end{array}$ & $29.7 \pm 7.1$ & $30.4 \pm 9.3$ & NS \\
\hline Vasodilator on emergence & $10(77)$ & $5(36)$ & $0.038 *$ \\
\hline Naloxone on emergence & $4(31)$ & $4(29)$ & NS \\
\hline
\end{tabular}

Parametric data analyzed by unpaired $t$ test.

Non-parametric data analyzed by Fisher's Exact Test.

Mean \pm SD for parametric data.

${ }^{*} P \leq 0.05$.

NS $=$ not significantly different.

lated bradycardia was treated with glycopyrrolate in 4 / 13 patients in Group Iso and 2/14 patients in Group Prop $(P=0.286)$. During the period of cross-clamping of the ICA, all patients had their blood pressure supported with phenylephrine infusion. More phenylephrine was administered to patients in Group Iso (3916 \pm 3182 $\mu \mathrm{g}$ versus $2702 \pm 1074 \mu \mathrm{g} ; P=0.005$ ). The end-tidal isoflurane concentration during cross-clamping was 0.62 \pm 0.13 volumes percent. The ICA cross-clamp time did not differ between groups $(29.7 \pm 7.1 \mathrm{~min}$ in Group Iso and $30.4 \pm 9.3 \mathrm{~min}$ in Group Prop; $P=0.361$ ). There was a greater use of vasodilator therapy on emergence from anaesthesia in Group Iso (10/13 patients versus 5/ $14 ; P=0.038$ ). The mean dose of labetalol administered was greater in this Group $(P=0.035)$. There was no difference in the requirement for naloxone administration on emergence in either group (4/13 in Group Iso and $4 / 14$ in Group Prop; $P=0.615$ ). Arterial blood gas analysis revealed a higher $\mathrm{PaCO}_{2}$ at two minutes postextubation in Group Iso (54.6 \pm 6.6 versus $47.3 \pm 14.8$ $\mathrm{mmHg} ; P=0.013$ ). At 5 and $30 \mathrm{~min}$ following extubation there was no difference in $\mathrm{PaCO}_{2}(P=0.357$ and 0.203 respectively). At extubation, in Group Iso, the mean anaesthetic concentration was $0.19 \pm 0.04$ volumes percent. Extubation times were slower in the propofol group at $12.2 \pm 8.3 \mathrm{~min}$ versus $6.3 \pm 4.6 \mathrm{~min}$ in Group Iso ( $P$ $=0.041$ ). However, no difference was found for the time to follow the command "squeeze my fingers" ( $9.8 \pm 7.3$ $\mathrm{min}$ and $6.5 \pm 4.9 \mathrm{~min}$ Group Prop and Iso respectively; $P=0.299$ ).

Haemodynamic data for one patient in Group Prop are graphically displayed in Figures $1 \mathrm{a}$ and $1 \mathrm{~b}$. Zero on the ordinate represents the target range of $80-120 \%$ of ward baseline HR and MAP respectively for this patient. 


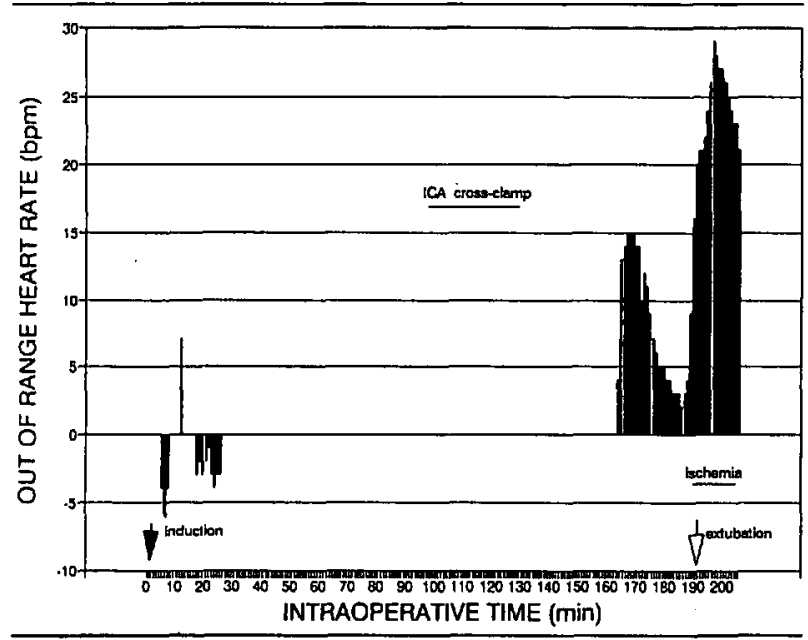

FIGURE la Out of range heart rate (beats $\cdot \mathrm{min}^{-1}$ ) versus intraoperative time in minutes for a patient receiving propofol (Patient 10; Table VI). Zero on the ordinate represents the target range of $80-120 \%$ of ward baseline heart rate for this patient ( 53 and 80 beats $\cdot \min ^{-1}$ respectively). The internal carotid was cross clamped for 29 minutes. The period of ischaemia with extubation lasted 8.3 minutes in this case. See text for further details.

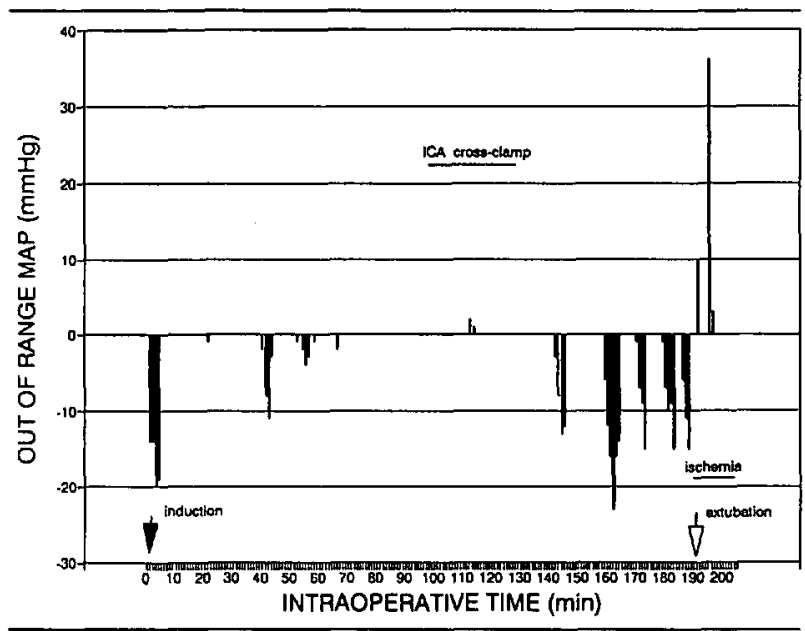

FIGURE lb Out of range mean arterial pressure $(\mathrm{mmHg})$ versus intraoperative time in minutes for a patient receiving propofol (Patient 10 , Table $\mathrm{VI}$ ). Zero on the ordinate represents the target range of $80-120 \%$ of ward baseline mean arterial pressure for this patient ( 82 and $124 \mathrm{mmHg}$ respectively). See text for further details.

This patient, who was four months post-infarction and had post-infarction angina, had angina on emergence from anaesthesia, which persisted for $8.3 \mathrm{~min}(1.4 \mathrm{~mm}$ of ST-segment depression in CS5). The HR at maximal ST-segment depression was 106 beats $\cdot \min ^{-1}$. Over the period of emergence from anaesthesia (time from reversal of neuromuscular blockade to leaving the operating theatre) when this patient demonstrated myocardial ischaemia, he had out of range tachycardia for $96 \%$ of time
TABLE IV Intraoperative haemodynamic stability

\begin{tabular}{lccl}
\hline Event & Isoflurane & Propofol & P-value \\
\hline Min HR (\%) & $37 \pm 32$ & $19 \pm 22$ & NS \\
Min HR (mag) & $5 \pm 4$ & $4 \pm 2$ & NS \\
Max HR (\%) & $3 \pm 4$ & $3 \pm 3$ & NS \\
Max HR (mag) & $5 \pm 5$ & $5 \pm 5$ & NS \\
Min MAP (\%) & $6 \pm 4$ & $6 \pm 6$ & NS \\
Min MAP (mag) & $6 \pm 4$ & $7 \pm 5$ & NS \\
Max MAP (\%) & $7 \pm 4$ & $6 \pm 7$ & NS \\
Max MAP (mag) & $8 \pm 4$ & $7 \pm 6$ & NS \\
\hline
\end{tabular}

Min HR $(\%)=$ mean percentage of time heart rate was below $80 \%$ of ward baseline values.

Min HR (mag) = mean magnitude (area under the curve) for heart rate that was below $80 \%$ of ward baseline values.

Max $=$ values above $120 \%$ of ward baseline values.

Beats $\cdot \mathrm{min}^{-1}$ for $\mathrm{HR}$ and $\mathrm{mmHg}$ for MAP.

Mean \pm SD for parametric data.

with a mean magnitude of 14 beats $\cdot \min ^{-1}$ and no out of range bradycardia. For MAP the patient was hypertensive $7 \%$ of the time with a magnitude of $16 \mathrm{mmHg}$ and hypotensive $36 \%$ of the time with a magnitude of $11 \mathrm{mmHg}$. Tachycardia and hypertension were treated with a total of $50 \mathrm{mg}$ labetalol, $2 \mathrm{mg}$ of propranolol and $300 \mu \mathrm{g}$ of nitroglycerine. Hypotension was treated with phenylephrine infusion. The chest pain resolved following these interventions.

\section{Intraoperative haemodynamic stability}

When all patients in the two groups were compared over the entire anaesthetic time course there was no difference between the two groups for haemodynamic stability (Table IV). Approximately 6000 data points $>200$ minute-by-minute recordings of HR and MAP for each of 27 experiments) were used to generate this table. Except for isolated bradycardia which was not treated aggressively, the percentage of time out of range for haemodynamic instability (increased HR or increased or decreased MAP) did not exceed $7 \%$ of the anaesthetic time course. The mean magnitude of out of range tachycardia was only 5 beats $\cdot \mathrm{min}^{-1}$ in both groups. Similar small out of range magnitudes were seen for hypotension or hypertension.

There was no difference in haemodynamic instability between groups for the induction period or during the period of ICA cross-clamping. No patient in either group had MAP values out of range $(110 \pm 10 \%$ of ward baseline values) during the period of cross-clamping of the ICA. All patients received phenylephrine for support of the blood pressure during this time. During emergence from anaesthesia, greater lability was seen in Group Iso with more hypertension (Table V; $P=0.005$ for per- 
TABLE V Emergence from anaesthesia haemodynamic stability

\begin{tabular}{lccl}
\hline Event & Isoflurane & Propofol & P-value \\
\hline Min HR (\%) & $29 \pm 28$ & $21 \pm 32$ & NS \\
Min HR (mag) & $3 \pm 3$ & $1 \pm 3$ & NS \\
Max HR (\%) & $14 \pm 21$ & $16 \pm 29$ & NS \\
Max HR (mag) & $5 \pm 5$ & $4 \pm 6$ & NS \\
Min MAP (\%) & $5 \pm 16$ & $17 \pm 23$ & NS \\
Min MAP (mag) & $1 \pm 3$ & $3 \pm 4$ & NS \\
Max MAP (\%) & $10 \pm 8$ & $3 \pm 5$ & $0.005^{*}$ \\
Max MAP (mag) & $9 \pm 5$ & $4 \pm 8$ & $0.004^{*}$ \\
\hline
\end{tabular}

Min HR $(\%)=$ mean percentage of time heart rate was below $80 \%$ of ward baseline values.

Min HR (mag) = mean magnitude (area over the curve) for heart rate that was below $80 \%$ of wand baseline values.

Max = values above $120 \%$ of ward baseline values.

Beats ' $\mathrm{min}^{-1}$ for $\mathrm{HR}$ and $\mathrm{mmHg}$ for MAP.

Mean \pm SD for parametric data.

$* P \leq 0.05$ Kruskal-Wallis Test (Chi-square approximation).

NS = not significantly different.

centage of time out of range at greater magnitude; $P$ $=0.004$ ).

\section{Perioperative ischaemia}

The perioperative episodes of myocardial ischaemia as assessed by Holter monitoring are shown in Table VI and graphically in Figure 2. In Group Prop, 2/14 patients had evidence of preoperative myocardial ischaemia. No patient in Group Iso had a preoperative ischaemic event (one patient had ST-segment depression of $0.9 \mathrm{~mm}$ and another ST-segment depression of $0.8 \mathrm{~mm}$ ). One patient in Group Iso had evidence of myocardial ischaemia on induction of anaesthesia. This was associated with a heart rate of 125 beats $\cdot \mathrm{min}^{-1}$ post-intubation. This patient also had ischaemia on emergence, again with poor control of heart rate ( 135 beats $\left.\cdot \mathrm{min}^{-1}\right)$. Of particular note is that no patient in either group had evidence of myocardial ischaemia as assessed by Holter monitoring during the period of blood pressure support with infused phenylephrine with cross-clamping of the carotid artery.

A clear difference in the incidence of myocardial ischaemia between the two groups was evident on emergence from anaesthesia. Fewer patients were ischaemic in Group Prop (1/14 versus 6/13; $P=0.029$ Fisher's Exact Test). The episodes of ischaemia which occurred were clearly related to tachycardia at extubation as was the episode of ischaemia on induction. Maximal HR with ischaemia was $107 \pm 17$ beats $\cdot \min ^{-1}$ for intraoperative events versus $70 \pm 14$ beats $\cdot \mathrm{min}^{-1}$ at other time periods ( $P=0.038$; see Table VI). All patients who had myocardial ischaemia at extubation had systolic blood pressures $>200 \mathrm{mmHg} ; 218 \pm 12 \mathrm{mmHg}$. Of the seven patients with Holter monitoring evidence of ischaemia on emergence from anaesthesia, $6 / 7$ received a $\beta$-blocker $i v$ during this time period (labetalol was administered because these six patients had hypertension as defined by the protocol). Mean labetalol dosage was greater in Group Iso $(P=0.035)$. The one patient not receiving labetalol was not hypertensive and there was no evidence of myocardial ischaemia at extubation by the intraoperative ECG.

\section{Postoperative complications}

To control MAP within $100 \pm 20 \%$ of ward baseline values 8/13 patients in Group Iso and 6/14 in Group Prop required phenylephrine in the intensive care unit ( $P=0.280$ between groups). In Group Iso, $1 / 13$ patients required some vasodilator therapy to treat hypertension; in Group Prop, $3 / 14$ patients $(P=0.327)$. One patient emerged from anaesthesia complaining of angina (see Figures la and $b$ for haemodynamic profile of this patient). He was treated as described above. The duration of postoperative Holter monitoring varied from $1.5 \mathrm{hr}$ (associated with battery failure) to $26.75 \mathrm{hr}$. The mean duration was $19.0 \pm 6.2 \mathrm{hr}$. Three patients in Group Iso had evidence of postoperative ischaemia and two in Group Prop $(P=0.462)$. These five patients had eight episodes of postoperative ischaemia. These episodes were more protracted than episodes of ischaemia intraoperatively (14.6 \pm 11.5 versus $3.1 \pm 2.3 \mathrm{~min}$ respectively; $P=0.015$, unpaired t test; see Table VI). One patient in Group Iso had an MB-CK of $36 \mathrm{U} \cdot \mathrm{L}^{-1}$ which represented $9 \%$ of total CK. This is considered elevated at our hospital but not diagnostic of perioperative myocardial infarction. The ECG was unchanged from before operation. No patient had ECG evidence of new $Q$-wave myocardial infarction. One patient in Group Prop developed congestive heart failure postoperatively which responded to two doses of furosemide $i v$.

No patient emerged from anaesthesia with evidence of a new neurological deficit. Two patients developed new deficits postoperatively. One developed neurological symptoms in the intensive care unit the evening following surgery after a period of hypotension (MAP $<60 \mathrm{mmHg}$ following overly aggressive antihypertensive therapy) with an absent carotid pulse on the operated side. Emergency re-exploration revealed a thrombus at the endarterectomy site which was removed. The patient recovered without neurological sequelae. The other patient had a stroke in the territory supplied by the internal carotid artery on the operated side eight days following surgery with angiographic evidence of embolism at this time.

\section{Ischaemic versus non-ischaemic patients}

When assessed $a$ posteriori, patients who demonstrated intraoperative ischaemia by Holter monitoring $(n=7)$ 
TABLE VI Perioperative ischaemic episodes for the two anaesthetics as assessed by Holter monitoring

\begin{tabular}{|c|c|c|c|c|}
\hline $\begin{array}{l}\text { Anaesthetic } \\
\text { patient \# }\end{array}$ & Event & $\begin{array}{l}\text { Max ST- } \\
\text { depression }(\mathrm{mm})\end{array}$ & $\begin{array}{l}\text { HR at Max-ST } \\
\text { depression }\end{array}$ & $\begin{array}{l}\text { Duration } \\
\text { (min) }\end{array}$ \\
\hline Isoflurane & Induction & -2.1 CS5 & 125 & 3.9 \\
\hline Patient \#4 & Extubation & $-2.1 \mathrm{CS} 5$ & 135 & 2.0 \\
\hline $\begin{array}{l}\text { Isoflurane } \\
\text { Patient \#5 }\end{array}$ & Post op $13 \mathrm{hr} 40 \mathrm{~min}$ & $-1.5 \operatorname{CS} 5$ & 81 & 25.6 \\
\hline $\begin{array}{l}\text { Isoflurane } \\
\text { Patient \#8 }\end{array}$ & Extubation & $-1.3 \operatorname{CS} 5$ & 85 & 3.4 \\
\hline Isoflurane & Extubation & $-2.0 \operatorname{CS} 5$ & 115 & 2.0 \\
\hline Patient \#9 & $\begin{array}{l}\text { Post op } 4 \mathrm{hr} 20 \mathrm{~min} \\
\text { Post op } 9 \mathrm{hr} 25 \mathrm{~min}\end{array}$ & $\begin{array}{l}-1.7 \text { CS5 } \\
-1.9 \operatorname{CS} 5\end{array}$ & $\begin{array}{l}78 \\
99\end{array}$ & $\begin{array}{l}7.7 \\
5.0\end{array}$ \\
\hline Isoflurane & Extubation & $-1.7 \operatorname{CS} 5$ & 102 & 2.1 \\
\hline Patient \#13 & Post op $35 \mathrm{~min}$ & $-2.1 \mathrm{CS} 5$ & 63 & 5.1 \\
\hline $\begin{array}{l}\text { Isoflurane } \\
\text { Patient } \# 19\end{array}$ & Extubation & $-1.1 \operatorname{CS} 5$ & 92 & 2.0 \\
\hline $\begin{array}{l}\text { Isoflurane } \\
\text { Patient } \# 24\end{array}$ & Extubation & $-2.9 \operatorname{CS} 5$ & 97 & 1.2 \\
\hline Propofol & Pre ind $3 \mathrm{hr} 44 \mathrm{~min}$ & $-1.8 \operatorname{Cs} 5$ & 62 & 17.0 \\
\hline Patient $\# 3$ & $\begin{array}{l}\text { Pre ind } 2 \mathrm{hr} 50 \mathrm{~min} \\
\text { Pre ind } 20 \mathrm{~min} \\
\text { Post op } 2 \mathrm{hr} 55 \mathrm{~min} \\
\text { Post op } 5 \mathrm{hr} 17 \mathrm{~min} \\
\text { Post op } 26 \mathrm{hr} 21 \mathrm{~min}\end{array}$ & $\begin{array}{l}-1.2 \text { CS5 } \\
-1.4 \text { CS5 } \\
-1.6 \text { CS5 } \\
-1.8 \text { CS5 } \\
-1.4 \text { CS5 }\end{array}$ & $\begin{array}{l}55 \\
64 \\
46 \\
74 \\
74\end{array}$ & $\begin{array}{l}12.0 \\
17.0 \\
14.0 \\
37.0 \\
16.0\end{array}$ \\
\hline $\begin{array}{l}\text { Propofol } \\
\text { Patient } \# 10\end{array}$ & Extubation & $-1.4 \operatorname{CS} 5$ & 106 & 8.3 \\
\hline $\begin{array}{l}\text { Propofol } \\
\text { Patient } \# 20\end{array}$ & $\begin{array}{l}\text { Pre ind } 28 \mathrm{~min} \\
\text { Post op } 2 \mathrm{hr} 31 \mathrm{~min}\end{array}$ & $\begin{array}{l}-1.6 \text { CS5 } \\
-1.8 \mathrm{IJ}\end{array}$ & $\begin{array}{l}71 \\
74\end{array}$ & $\begin{array}{l}1.6 \\
6.5\end{array}$ \\
\hline
\end{tabular}

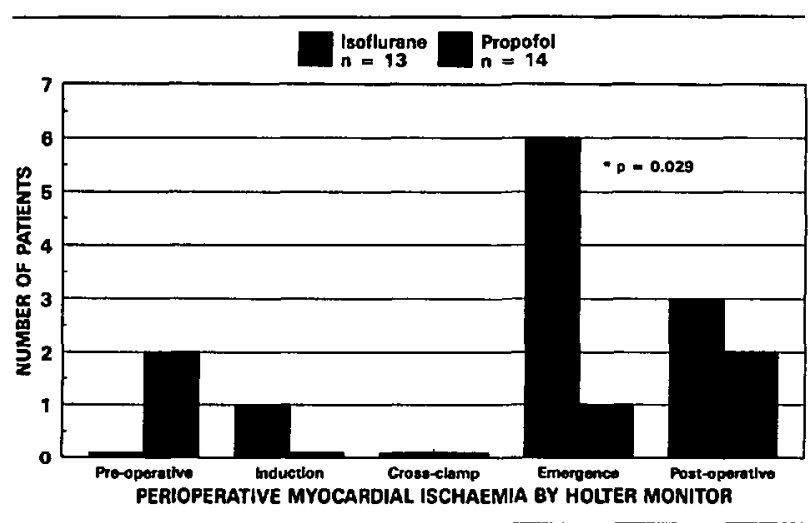

FIGURE 2 Perioperative ischaemic episodes for both groups of patients as assessed by Holter monitoring of leads II and CS5. More patients in the group receiving isoflurane were ischaemic on emergence from anaesthesia $(P=0.029$; Fisher's Exact Test). Note that no patient in either group was ischaemic during the intraoperative period which includes the time of internal carotid artery cross-clamping with phenylephrine support of the blood pressure.

were compared with those who did not $(n=20)$ using similar statistical analyses as described above. No differences for demographics or perioperative medications were seen. Greater doses of labetalol were administered to ischaemic patients on emergence $(P=0.016)$.

\section{Discussion}

In this study we examined indices of haemodynamic instability during general anaesthesia for CEA. We defined haemodynamic instability to be HR or MAP $<80$ or $>120 \%$ of ward baseline values as assessed intraoperatively every minute. Two different anaesthetic regimens were compared; propofol/alfentanil and thiopentone/isoflurane/alfentanil. Approximately 6000 measurements of intraoperative HR and MAP were obtained. Although somewhat arbitrary, our definition for intraoperative haemodynamic instability correlated to intraoperative episodes of myocardial ischaemia as assessed by Holter monitoring. On emergence from anaesthesia, we have shown greater haemodynamic stability, with decreased need for pharmacological intervention, and fewer episodes of myocardial ischaemia in patients given propofol. Based on these findings is propofol a superior general anaesthetic agent to isoflurane for CEA? Our study does not permit a definitive conclusion because, when assessed over the entire anaesthetic course, there was no difference in haemodynamic stability between groups. Most importantly, there was no difference in outcome with regards to myocardial morbidity between groups, although this study has inadequate statistical power to assess such differences definitively. 
That propofol anaesthesia could be associated with a smoother emergence is supported by pharmacokinetic and pharmacodynamic studies. Vuyk et al. showed that propofol/alfentanil resulted in decreased $\mathrm{EC}_{50}$ (the concentration at which, with a $50 \%$ probability, patients did not respond to surgical stimuli) compared with $\mathrm{N}_{2} \mathrm{O}$ /alfentanil suggesting anaesthetic synergism with propofol/ alfentanil. ${ }^{8}$ Vinik et al. showed that propofol/alfentanil had a superadditivity factor of 1.4 compared with either agent alone and that midazolam/propofol/alfentanil were superadditive to a factor of $2.6^{9}$ Both groups of patients in our study were premedicated with midazolam, suggesting that the synergism in Group Prop may be similar to the triple anaesthetic combination used by Vinik $e t$ al. Further evidence that alfentanil/propofol effectively controls hyperdynamic haemodynamic responses is offered by Monk et al. ${ }^{2}$ When haemodynamic alterations were controlled by varying the propofol infusion against a constant alfentanil infusion, rather than vice versa, 75\% fewer patients required antihypertensive therapy in the immediate postoperative period. In our study, the propofol infusion rate was varied against a constant infusion of alfentanil.

Propofol may also have provided protection from a hyperdynamic emergence due to the surprising finding of delayed emergence in this group. Emergence from isoflurane anaesthesia in the presence of doses of alfentanil as used in this study is usually within two to five minutes if end-tidal isoflurane concentration is approximately 0.15 volumes percent. ${ }^{3}$ Mean end-tidal isoflurane concentration at extubation was $0.19 \pm 0.04$ volumes percent in this study. Delayed emergence with higher concentrations of isoflurane has previously been shown to be associated with less, not more, haemodynamic stability on emergence. In neurosurgical patients the combination of higher end-tidal isoflurane with lower infusion rates of alfentanil was associated with greater requirements for vasodilator therapy on emergence from anaesthesia. ${ }^{3}$ Thus, it seems unlikely that the slower emergence with propofol conferred an advantage of haemodynamic stability. The study by Vuyk et al. ${ }^{8}$ indicates a very tight $\mathrm{EC}_{50}$ for various surgical stimuli, perhaps suggesting a mechanism for haemdynamic stability on emergence. Propofol when used for sedation is associated with lower levels of circulating catecholamines than that seen using other agents. ${ }^{10}$ Similar concentrations to that seen when propofol is used for sedation would be present during emergence from anaesthesia and may help to explain the more stable haemodynamics in this group.

There is a lack of consistency in the literature as to when ischaemia during the perioperative period affects outcome. The largest study by Mangano et al. involving 474 patients showed that postoperative myocardial mor- bidity best correlated with postoperative myocardial ischaemia using multivariate analysis techniques. " However, preoperative, intraoperative and postoperative ischaemia as assessed by Holter monitoring were all univariate predictors of outcome. In their hands, the Holter monitor was a very sensitive indicator of intraoperative myocardial ischaemia. ${ }^{12}$ In contrast, Pasternack et al., again using a Holter monitoring system, demonstrated that only preoperative silent ischaemia and rest angina were multivariate predictors of postoperative MI. ${ }^{13}$ They used a QMED system (frequency response $0.05-40 \mathrm{~Hz}$ ) monitoring lead $\mathrm{CM}_{5}$. That system uses a computer algorithm to define ischaemia as ST-segment depression $>0.1 \mathrm{mV}$ for $>40 \mathrm{sec}$. Their study is germane to this discussion because a large subgroup of patients $(n=80)$ underwent carotid endarterectomy. In our study, intraoperative myocardial ischaemia correlated with haemodynamic instability on emergence (especially at the time of extubation). These results suggest that treatment of the hyperdynamic emergence by $\beta$-blockade may also provide treatment of emergence myocardial ischaemia. The intraoperative periods of myocardial ischaemia which correlated to haemodynamic instability were short lived (3.1 $\pm 2.3 \mathrm{~min})$. With emergence, haemodynamic instability in $6 / 7$ patients was pharmacologically treated with the mixed $\alpha$ - and $\beta$-receptor antagonist, labetalol. Whether or not these ischaemic episodes would have been self-limited if not treated aggressively cannot be answered. We have also shown that postoperative ischaemia is common following carotid endarterectomy (19\% of patients) and may persist for protracted periods.

In our study, no patient was ischaemic as assessed by Holter monitoring during the period of ICA crossclamping when MAP was supported with a phenylephrine infusion. Previous work by Smith $e t a l$. showed that myocardial ischaemia (as identified by new segmental wall motion abnormalities on transoesophageal echocardiograms, TEE), occurred frequently (33\%; $13 / 39$ patients) during CEA, when phenylephrine was administered to support the blood pressure with either moderately deep levels of halothane or isoflurane anaesthesia (approximately $0.85 \mathrm{MAC}$ end-tidal concentrations). ${ }^{14}$ Our results differ considerably from those of Smith et al. $(P=0.0004$; Fisher's Exact Test). The "Rule of Threes" states that when an event is not observed in $n$ trials, then the $95 \%$ confidence intervals dictate that the maximal possible incidence of the event $(\alpha=0.05)$ is given by $1 /(n / 3) .^{15}$ In this instance, $1 /(27 / 3)$ or $11 \%$ of patients could have demonstrated ischaemia. Even if we were to assume the worse case scenario with $3 / 27$ patients having evidence of myocardial ischaemia, there would still remain a difference between the results in the two studies $(P=0.035$ by Fisher's Exact Test). Possibly, our failure to demon- 
strate myocardial ischaemia during this time may relate to the Holter monitor being less sensitive than the TEE but, we have demonstrated that Holter monitoring is a sensitive means of detecting ischaemia at other times during the intraoperative course in this study. Eisenberg et al. showed that Holter monitoring was more sensitive than either 12-lead ECG or TEE for detection of intraoperative myocardial ischaemia. ${ }^{12}$ Smith $e t$ al. mentioned the possibility that changes in ventricular loading could have influenced the interpretation of their TEE results. Marked alterations in both end systolic and diastolic volumes are to be anticipated in the situation where a pure $\alpha_{1}-$ adrenergic agonist is administered in the presence of potent negative inotropes such as volatile anaesthetics.

The differences between these two studies can only be resolved if simultaneous Holter and TEE monitoring are performed in patients undergoing CEA. The controversy needs to be resolved, because a number of current anaesthesia textbooks state that support of the blood pressure during cross-clamping is contraindicated because of the risk of myocardial ischaemia, largely based on the study by Smith et al..$^{16-18}$ Based on their work, it is suggested that blood pressure should not be elevated so that the heart is protected from the risk of ischaemia. Such management is not felt to place the brain at risk if the intraoperative EEG indicates no evidence of ischaemia (EEG slowing or changes in amplitude). This recommendation only has merit if the incidence of falsely negative EEG results is very low. Two studies indicate that the incidence of stroke following falsely negative EEG results are $1.5-3.0 \%{ }^{19,20}$ This incidence of stroke is close to or exceeds the acceptable range suggested by the NASCET study $(2.1 \%){ }^{7}$ It is very important to note that in both of these studies, ${ }^{19,20}$ patients were monitored with 16 lead EEG systems. It is likely that less rigorous monitoring of the EEG, such as two-channel systems, where the EEG signal is processed would have a higher false negative rate. If, as our study shows, support of the blood pressure with phenylephrine does not place the heart at increased risk during the period of ICA cross-clamping, cerebral perfusion pressure can be optimally supported. Animal work indicates that in the presence of isoflurane anaesthesia, elevation of blood pressure with phenylephrine increases cerebral blood flow. ${ }^{21}$

Although randomized, our study can be criticized because the anaesthetist was not blinded to the anaesthetic administered which could lead to experimenter bias. While not impossible to conduct a blinded study, this would be very difficult to accomplish in the clinical environment. The anaesthetist or anaesthesia residents directly responsible for patient management were informed of the haemodynamic target ranges and pharmacological interventions permitted and then they were responsible for conduct of the anaesthetic. Greater concentrations of phenylephrine were administered to patients in Group Iso during the period of ICA cross-clamping. Therefore, it is possible that the greater use of vasodilators on emergence in this group could simply reflect a residual effect of phenylephrine. This seems unlikely, however, as the mean dose of phenylephrine given to patients in Group Iso who did and did not require vasodilators on emergence was not different $(3630 \pm 3330$ vs $4290 \pm 2480$ $\mu \mathrm{g}$ respectively; $P=0.721$ ). There was no difference in the incidence or treatment of post-induction hypotension, nor in the frequency of administration of naloxone on emergence. Since haemodynamic stability for the entire course of the anaesthetic was not different between groups, this strongly suggests that choice of anaesthetic did not bias our management. The finding of delayed extubation with propofol was unexpected which suggests that we were not biased in our measurement of emergence times. The Holter monitor tapes were analysed in a blinded fashion post hoc. In addition, haemodynamic data were analyzed independently of the Holter monitor tapes and only collated and analyzed $a$ posteriori.

In summary, we assessed the incidence and magnitude of haemodynamic instability during CEA using two different general anaesthesia regimens. Both HR and MAP could be maintained within narrow ranges with both isoflurane/thiopentone/alfentanil and propofol/alfentanil anaesthesia when the entire time course of anaesthesia was examined. Despite good overall haemodynamic control there was a $26 \%$ incidence of intraoperative myocardial ischaemia as assessed by Holter monitoring. No myocardial ischaemic episodes occurred in either group during the period of pharmacologically augmented blood pressure when the internal carotid artery was crossclamped. However, on emergence from anaesthesia, patients anaesthetized with propofol were more stable haemodynamically and had a decreased requirement for treatment of hypertension with a lower incidence of myocardial ischaemia. The ischaemic events concurrently with extubation were short-lived but were aggressively treated with pharmacological agents. There was no difference in cardiac morbidity between groups.

We conclude that support of the blood pressure with phenylephrine during cross-clamping of the internal carotid artery, in an attempt to augment cerebral perfusion pressure, is a safe procedure which does not place the heart at increased risk of ischaemia during carotid endarterectomy. Patients are at risk of haemodynamic instability with myocardial ischaemia during emergence from anaesthesia for carotid endarterectomy. Investigations, to assess if interventions to decrease perioperative ischaemia with a view to improved cardiac outcome, appear to be warranted in this high risk group of patients. 
In addition, further study of the potential advantage of midazolam/propofol/alfentanil anaesthesia or similar triple anaesthetic combinations for vascular surgical procedures appears worthwhile.

\section{Acknowledgements}

The authors thank sincerely the patients who participated in this study; in many instances this was just one of three studies in which they took part. We also thank Drs. D.B. Craig, L.G. Brownell, G.S. MacKenzie, and M.R. Graham for helpful discussions during preparation of the manuscript. Special thanks to Dr. R.M. Friesen for provision of the Siemens monitors and software.

\section{References}

1 Roizen $M F$. Anesthesia goals for operations to relieve or prevent cerebrovascular insufficiency. In: Roizen MF (Ed.). Anesthesia for Vascular Surgery. New York: Churchill Livingstone Inc., 1990; 104-5.

2 Monk TG, Ding Y, White PF. Total intravenous anesthesia: effects of opioid versus hypnotic supplementation on autonomic responses and recovery. Anesth Analg 1992; 75: 798-804.

3 Mutch WAC, Ringaert KRA, Ewert FJ, White IWC, Donen N, Hudson RJ. Continuous opioid infusions for neurosurgical procedures: a double-blind comparison of alfentanil and fentanyl. Can J Anaesth 1991; 38: 710-6.

4 Doze VA, Westphal LM, White PF. Comparison of propofol with methohexital for outpatient anesthesia. Anesth Analg 1986; 65: 1189-95.

5 Reddy $K$, West $M$, Anderson B. Carotid endarterectomy without indwelling shunts and intraoperative electrophysiologic monitoring. Can J Neurol Sci 1987; 14: 131-5.

6 Sundt TM Jr, Sandok BA, Whisnant JP. Carotid endarterectomy. Complications and preoperative assessment of risk. Mayo Clin Proc 1975; 50: 301-6.

7 North American Symptomatic Carotid Endarterectomy Trial Collaborators. Beneficial effect of carotid endarterectomy in symptomatic patients with high-grade carotid stenosis. N Engl J Med 1991; 325: 445-53.

8 Vuyk J, Lim T, Engbers FHM, Burm AGL, Vetter AA, Bovill JG. Pharmacodynamics of alfentanil as a supplement to propofol or nitrous oxide for lower abdominal surgery in female patients. Anesthesiology 1993; 78: 1036-45.

9 Vinik HR, Bradley EL Jr, Kissin I. Triple anesthetic combination: propofol-midazolam-alfentanil. Anesth Analg 1994; 78: 354-8.

10 Beyer $R$, Seyde WC. Propofol versus Midazolam. Langzeitsedierung auf der Intensivstation. Anaesthesist 1992; 41 : 335-41.

11 Mangano DT, Browner WS, Hollenberg $M$, et al. Association of perioperative myocardial ischemia with car- diac morbidity and mortality in men undergoing noncardiac surgery. N Engl J Med 1990; 323: 1781-8.

12 Eisenberg $M J$, London $M J$, Leung $J M$, et al. Monitoring for myocardial ischemia during noncardiac surgery. A technology assessment of transesophageal echocardiography and 12-lead electrocardiography. JAMA 1992; 268: 210-6.

13 Pasternack PF, Grossi EA, Baumann $G$, et al. The value of silent myocardial ischemia monitoring in the prediction of perioperative myocardial infarction in patients undergoing peripheral vascular surgery. J Vasc Surg 1989; 10: 617-25.

14 Smith JS, Roizen MF, Cahalan MK, et al. Does anesthetic technique make a difference? Augmentation of systolic blood pressure during carotid endarterectomy: effects of phenylephrine versus light anesthesia and of isoflurane versus halothane on the incidence of myocardial ischemia. Anesthesiology 1988; 69: 846-53.

15 Fisher LD, van Belle G. Biostatistics: A Methodology for the Health Sciences. New York: John Wiley \& Sons, 1993; 231.

16 Clark NJ, Stanley TH. Anesthesia for vascular surgery. In: Miller RD (Ed.). Anesthesia, 3rd ed. New York: Churchill Livingstone Inc., 1990; 1693-713.

17 Michenfelder JD Anesthesia and surgery for cerebrovascular insufficiency: one approach at the Mayo Clinic. In: Roizen MF (Ed.). Anesthesia for Vascular Surgery. New York: Churchill-Livingstone Inc., 1990: 123-34.

18 Roizen $M F$, Ellis JE. Anesthesia for vascular surgery. In: Barash PG, Cullen BF, Stoelting RK (Eds.). Clinical Anesthesia, 2nd ed. Philadelphia: JB Lippingcott Inc., 1992; 1065-6.

19 McFarland HR, Pinkerton JA Jr, Frye D. Continuous electroencephalographic monitoring during carotid endarterectomy. J Cardiovasc Surg 1988; 29: 12-8.

20 Kresowik $T F$, Worsey $M J$, Khoury $M D$, et al. Limitations of electroencephalographic monitoring in the detection of cerebral ischemia accompanying carotid endarterectomy. J Vasc Surg 1991; 13: 439-43.

21 Patel PM, Mutch WAC. The cerebral pressure-flow relationship during 1.0 MAC isoflurane anesthesia in the rabbit: the effect of different vasopressors. Anesthesiology 1990; 72: 118-24. 